\title{
Wpływ robotyzacji na rynek pracy i sektor ubezpieczeń społecznych
} The impact of robotization on the labour market
and social protection

\author{
dr Marcin Rojszczak \\ Uniwersytet Warszawski, Wydział Prawa i Administracji, \\ Instytut Nauk Prawno-Administracyjnych \\ ORCID: 0000-0003-2037-4301 \\ e-mail: marcin.rojszczak@pbsg.pl
}

\begin{abstract}
Streszczenie Współczesna gospodarka w znacznym stopniu opiera się na wykorzystaniu rozbudowanych algorytmów automatyzujących podejmowane decyzje. Coraz częściej mówi się o wykorzystaniu takich technologii jak sztuczna inteligencja czy uczenie maszynowe, których praktyczne zastosowanie będzie prowadziło do dalszego zwiększenia wydajności procesów wytwórczych, ale również wprowadzenia nowych — nieznanych wcześniej form i sposobów świadczenia usług. Obserwowane procesy cyfryzacji gospodarki, wykorzystujące na nieznaną wcześniej skalę automatyzację oraz systemy informatyczne wyposażone w możliwość samodzielnego podejmowania decyzji, stanowią nowy argument $w$ ponad stuletniej dyskusji dotyczącej istnienia oraz skali fenomenu technologicznego bezrobocia. Zagadnienie to zyskuje jednak inny jakościowo wymiar w związku z potencjałem związanym z nowymi technikami przetwarzania informacji. Zdaniem autora koncepcja „świata bez pracy” powinna być coraz częściej przedmiotem dyskusji nie tylko wśród socjologów czy ekonomistów, ale z uwagi na realne i daleko idące implikacje dla gospodarki i państwa także wśród prawników.
\end{abstract}

Słowa kluczowe: technologiczne bezrobocie, robotyzacja, opodatkowanie robotów, świat bez pracy, gwarantowany dochód minimalny.

Summary The observed processes of the digitization of the economy, using automation on previously unknown scale and IT systems equipped with the ability to make independent decisions, constitute a new argument in over one hundred years of discussion regarding the existence and the scale of technological unemployment phenomena. This issue, however, gains a different scale due to the potential associated with new information processing techniques. As a result, the concept of "world without a job" should be more often discussed not only by sociologists or economists - but because of the real and far - reaching implications for the economy and the state, also by lawyers.

Keywords: technological unemployment, robotization, taxation of robots, world without work, guaranteed minimum income.

JEL: K24

Str. 5-14 


\section{Bibliografia}

Abbott, R. Bogenschneider, B. (2018). Should Robots Pay Taxes? Tax Policy in the Age of Automation. Harvard Law \& Policy Review, 12, https://doi.org/10.2139/ssrn.2932483

Afeltowicz, Ł. (2007). Czy technika pozbawia nas pracy? Bezrobocie technologiczne w perspektywie teorii aktora-sieci. Studia Socjologiczne, (184).

Allen, T. Widdison, R. (1996). Can Computers Make Con- tracts? Harvard Journal of Law \& Technology, (1).

Batorski, D. (2015). Warunki życia gospodarstw domowych. Wpływ nowych technologii na rynek pracy — pozycja użytkowników i bezrobocie technologiczne. Contemporary Economics, (4).

Bejma, U. (2015). Praca jako wartość w życiu człowieka. Wybrane aspekty. Periodyk Naukowy Akademii Polonijnej, 4.

Borkowska, S. (2010). Równowaga między pracą a życiem pozazawodowym. Acta Universitatis Lodziensis. Folia Oeconomica, (240).

Bureau of Labor Statistics. (2018). Employment Projections. Bureau of Labor Statistics, https://data.bls.gov/projections/occupationProj (23.10.2018).

Calo, R. (2015). Robotics and the Lessons of Cyberlaw. California Law Review, 103.

Campa, R. (2017). Technological Unemployment. A Brief History of an Idea. International Sociological Association - forum ISA eSymposium for Sociology, https://ruj.uj.edu.pl/xmlui/ handle/item/46288 (23.10.2018).

Cieślukowski, M. (1998). Ekonomiczne skutki i metody ograniczania bezrobocia. Ruch Prawniczy, Ekonomiczny i Socjologiczny, (3-4).

Cylka, T. (2018). Bardzo inteligentny stetoskop. Pomysł urodził się na Facebooku. Gazeta Wyborcza z 7.05.2018, http://cli.re/gvJKQg (23.10.2018).

Dach, Z. (2008). Przemiany współczesnych rynków pracy. Polskie Towarzystwo Ekonomiczne - Zeszyty Naukowe, (6).

Delcker, J. (2018). Europe divided over robot 'personhood'. Politico z 11.04.2018, http://cli.re/GRnNAE (23.10.2018).

Desilver, D. (2018). For most U. S. workers, real wages have barely budged in decades. Pew Research Center z 7.08.2018, http://cli.re/gKaEE2 (23.10.2018).

Future Advocacy. (2017). The Impact of AI in UK Constituencies: Where will automation hit hardest? Future Advocacy, http://cli.re/GYe2wn (23.10.2018).

Gartner. (2017). Gartner Says by 2020, Artificial Intelligence Will Create More Jobs Than It Eliminates. Gartner 13.12.2017, https://www.gartner.com/newsroom/id/3837763 (23.10.2018).

Geistfeld, M. (2017). A Roadmap for Autonomous Vehicles: State Tort Liability, Automobile Insurance, and Federal Safety Regulation. California Law Review, (6).

Gołębiowski, G. (2017). Powszechny dochód podstawowy — argumenty za i przeciw. Studia Ekonomiczne, (334).

Graetz, G. Michaels, G. (2017). Is Modern Technology Responsible for Jobless Recoveries? American Economic Review Papers and Proceedings, (5), https://doi.org/10.1257/aer.p20171100

Griffin, A. (2017). Saudi Arabia Grants Citizenship to a Robot for the First Time Ever. The Independent z 26.10.2017, http://cli.re/G7X22y (23.10.2018).

Husson, M. (2006). Koniec pracy i powszechny dochód? Le Monde diplomatique Edycja Polska, (9), https://www.mondediplomatique.pl/LMD9/index.php?id=1 (23.10.2018).

IAR. (2017). Mateusz Morawiecki przytakuje Billowi Gatesowi. Chce opodatkować roboty. Business Insider Polska z 28.03.2017, http://cli.re/G8P9WR (23.10.2018).

ISO 8373: 2012, Robots and robotic devices — Vocabulary.

Karnow, C. (1996). Liability for Distributed Artificial Intelligences. Berkeley Technology Law Journal, (1).

Korea's Robot Tax. (2017). The Robotics Law Journal z 24.08.2017, http://cli.re/gXnYYr (23.10.2018).

Krygier, N. Karczmarz, P. (2011). Systemy agentowe w zarządzaniu wiedzą. Acta Universitatis Lodziensis. Folia Oeconomica, (261).

Levin, S. Carrie, J. (2018). Self-driving Uber kills Arizona woman in first fatal crash involving pedestrian. The Guardian z 19.03.2018, http://cli.re/g81v4n (23.10.2018).

Lipton, P. (2014). The Mythology of Salomon's Case and the Law Dealing with the Tort Liabilities of Corporate Groups: An Historical Perspective. Monash University Law Review, (2), https://doi.org/10.2139/ssrn.2605733

Mazur, J. (2017). Rząd przyjąt projekt ustawy o robotyzacji. Prawo.pl z 31.05.2017, http://cli.re/gRnEjZ (23.10.2018).

Mazur, O. (2018). Taxing the Robots. SMU Dedman School of Law Legal Studies Research Paper, (401), https://ssrn.com/abstract=3231660 (23.10.2018).

McKinsey Global Institute. (2017). A Future That Works: Automation, Employment, and Productivity. McKinsey Global Institute, http://cli.re/gnBvY5 (23.10.2018).

Oberson, X. (2017). Taxing Robots? From the Emergence of an Electronic Ability to Pay to a Tax on Robots or the Use of Robots. World Tax Journal, (2).

Onishi, N. (2006). In a Wired South Korea, Robots Will Feel Right at Home. The New York Times z 2.04.2006, http://cli.re/L3meEa (23.10.2018).

Organiściak-Krzykowska, A. (2012). Rola bezpośrednich inwestycji zagranicznych w kształtowaniu sytuacji na regionalnym rynku pracy. Acta Universitatis Lodziensis. Folia Oeconomica, (268).

Parlament Europejski. European Civil Law Rules in Robotics, PE 571.379, Bruksela: Parlament Europejski.

Parlament Europejski. (2017). Rezolucja Parlamentu Europejskie- go z dnia 16.02.2017 r. zawierająca zalecenia dla Komisji w sprawie przepisów prawa cywilnego dotyczacych robotyki (2015/2103 (INL)). Tekst polski: http://cli.re/LZe3Jr (23.10.2018).

Pasquale, F. Cashwell, G. (2015). Four Futures of Legal Automation. UCLA Law Review Discourse, 63. 
Pol, E. Reveley, J. (2017). Robot induced technological unemployment: towards a youth-focused coping strategy. Psychosociological Issues in Human Resource Management, (2).

Rotman, D. (2013). How Technology Is Destroying Jobs. MIT Technology Review, (4), http://cli.re/GJnZBE (23.10.2018).

Scherer, M. (2016). Regulating Artificial Intelligence Systems: Risks, Challenges, Competencies, and Strategies. Harvard Journal of Law \& Technology, (2), https://doi.org/10.2139/ssrn.2609777

Serenko, A. Ruhi, U. Cocosila, M. (2007). Unplanned effects of intelligent agents on Internet use: A social informatics approach. AI \& Society, (21), https://doi.org/10.1007/s00146-006-0051-8

Shubhendu, S. Vijay, J. (2013). Applicability of Artificial Intelligence in Different Fields of Life. International Journal of Scientific Engineering and Research, (1).

Solum, L. (1992). Legal Personhood for Artificial Intelligences. North Carolina Law Review, (4).

Stahl, A. (2018). Seven Top In-Demand Jobs in 2018. Forbes z 26.03.2018, http://cli.re/g4zdKG (23.10.2018), https://doi.org/10.1055/s-0036-1595061

Thompson, D. (2015). A World Without Work. The Atlantic, (7-8), http://cli.re/GK5Xdg (23.10.2018).

UN News. (2017). At UN, robot Sophia joins meeting on artificial intelligence and sustainable development. UN News z 11.10.2017, http://cli.re/G7w1zr (23.10.2018).

Urbi, J. Sigalos, M. (2018). The complicated truth about Sophia the robot - an almost human robot or a PR stunt. CNBC z 5.06.2018, http://cli.re/LZ4KoP(23.10.2018).

U.S. News \& World Report. (2017). The 100 Best Jobs, http://cli.re/LNmowQ (23.10.2018).

West, D. (2015). What happens if robots take the jobs? The im- pact of emerging technologies on employment and public policy. Center for Technology Innovation at Brookings, http://cli.re/Gr9NAQ (23.10.2018).

WUP w Krakowie. (2017). Barometr zawodów 2018. Raport podsumowujacy badanie w Polsce. Kraków: Wojewódzki Urząd Pracy.

Zarzycki, M. (2017). Bezwarunkowy dochód podstawowy — przyszłość prawa pracy i ubezpieczeń społecznych czy utopia? Praca $i$ Zabezpieczenie Społeczne, (6). 